\title{
O direito ao Autorreconhecimento na reafirmação étnica na região do Tapajós, Santarém-PA
}

\section{El derecho al Autorreconocimiento en la reafirmación étnica en la región de Tapajós, Santarém-PA}

\author{
Domingos Bruno Gonçalves Marques ${ }^{1}$
}

\begin{abstract}
Resumo: A Constituição Federal de 1988 reconheceu direitos aos povos indígenas como o direito ao território e à reprodução cultural. Em consonância com a Constituição, a Convenção no 169 da OIT também previu diversos direitos culturais como o direito ao autorreconhecimento. $O$ reconhecimento desses direitos favoreceu ao surgimento de um fenômeno social denominado de etnogênese que se liga diretamente com o direito fundamental ao autorreconhecimento. Esse fenômeno de cunho sócio-jurídico marca a realidade da região do Tapajós onde várias comunidades ribeirinhas passaram a se autodeclarar como indígenas sendo, portanto, de fundamental importância conhecer este fenômeno e suas implicações para a garantia de direitos fundamentais dessas comunidades. Palavras-chave: Ressurgimento étnico, autorreconhecimento, garantia de direitos.
\end{abstract}

\begin{abstract}
La Constitución Federal de 1988 reconoció derechos a los pueblos indígenas como el derecho al territorio ya la reproducción cultural. En consonancia con la Constitución, el Convenio no 169 de la OIT también previó diversos derechos culturales como el derecho al autorreconocimiento. El reconocimiento de esos derechos favoreció al surgimiento de un fenómeno social denominado de etnogénesis que se vincula directamente con el derecho fundamental al autorreconocimiento. Este fenómeno de carácter socio-jurídico marca la realidad de la región del Tapajós donde varias comunidades ribereñas pasaron a se autodeclarar como indígenas siendo, por lo tanto, de fundamental importancia conocer este fenómeno y sus implicaciones para la garantía de derechos fundamentales de esas comunidades.
\end{abstract}

Keywords: Reafirmación étnica, auto-reconocimiento, garantía de derechos.

\section{Introdução}

O presente trabalho buscou investigar a relação existente entre o direito ao autorreconhecimento e o fenômeno social de emergência étnica na região do Tapajós em Santarém-PA. A investigação adotou como perspectiva de abordagem a garantia do direito fundamental ao autorreconhecimento como estratégia de luta pelo território. Fez-se essa análise à luz da Convenção no 169 da Organização Internacional do Trabalho (OIT).

\footnotetext{
${ }^{1}$ Mestre em Direitos Humanos e Meio Ambiente pelo Instituto de Ciência Jurídica da UFPa; Professor da Faculdade Estácio Castanhal. dombrunomarques@hotmail.com
} 
A abordagem sobre a Convenção $n^{\circ} 169$ da OIT visa demonstrar a evolução na compreensão dos direitos indígenas ocasionado pela mobilização desses povos que por meio de sua luta conseguiram obstaculizar o inexorável processo de integração dos povos indígenas à cultura ocidental, impondo dessa forma seu desejo de manter e reproduzir seus costumes e tradições.

A Convenção no 169 é o marco jurídico internacional do direito ao autoreconhecimento. As condições que levaram a sua concepção, permitiram uma mudança de paradigma na relação entre Estados e povos indígenas. O Estado passou a ser o garantidor dos direitos étnicos por força da Convenção. O Brasil se tornou signatário da Convenção por meio do Decreto Presidencial 5.051/2014 e esse direito passou a ter eficácia jurídica no Brasil, sendo, assim, exigível. O ordenamento jurídico autóctone compreende o autorreconhecimento como único critério de identificação racial e étnico.

O artigo faz referência às circunstâncias sociais, históricas e políticas que contribuíram para fazer com que os índios do Tapajós fossem levados a ressignificar sua identidade étnica a ponto de até mesmo negá-la, bem como as circunstâncias que levaram essas mesmas pessoas a exaltar o seu orgulho de ser indígena.

As políticas integracionistas, que marginalizaram os povos indígenas, não se limitaram aos períodos colonial e imperial, com a proclamação da República, o mesmo viés etnocêntrico na relação entre o Estado e os indígenas persistiu. Mesmo as instituições de apoio aos índios brasileiros do período republicano SPI e FUNAI mantiveram uma perspectiva etnocêntrica em suas políticas de defesa dos interesses indígenas. Essa forma de relação entre os povos indígenas e o Estado perdurou até a promulgação da Constituição Federal de 1988.

Como consequência desse predatório e secular processo de assimilação da cultura indígena pela cultura europeia, a sociedade e o Estado passaram a não mais considerar índio quem não apresentasse os sinais diacríticos dos índios do período colonial, criou-se o mito do índio puro, "[...] a imagem que o público em geral tem da forma de vida das sociedades indígenas é estática: indivíduos vivendo em pequenas aldeias isoladas na floresta, representando um passado remoto, uma etapa evolutiva, enfim, população sem história" (MACEDO apud NEVES, 2009, p. 85). 
Ao contrário, muitas comunidades indígenas que foram integradas, buscam agora reedificar sua identidade étnica diante da possibilidade da realização de direitos proporcionados pela garantia do direito fundamental ao autorreconhecimento.

\section{Os direitos culturais previstos na Convenção $n^{\circ} 169$ da OIT}

A preocupação da Convenção $\mathrm{n}^{0} 169$ da OIT com direitos culturais está expressa já no primeiro artigo que trata das "Condições Gerais". Essa orientação segue por outros artigos como o artigo $2^{\circ}$, parágrafo 2, alínea b: "promover a plena realização dos direitos sociais, econômicos e culturais desses povos, respeitando sua identidade social e cultural, seus costumes e tradições e suas instituições (OIT, CONVENÇÃO nº 169, 1989, grifo nosso).

Ao determinar a garantia desses direitos, a Convenção estabelece alguns, os quais, sem sua realização, não é possível proteger direitos culturais, a saber: Direito a autoidentificação expresso no artigo $1^{\circ}$, parágrafo 2; direito à consulta prévia, livre e informada expresso no artigo 60; direito ao pluralismo jurídico expresso no artigo $9^{\circ} \mathrm{e}$ direito ao território previsto na Parte II da Convenção.

Dentre esses direitos que corroboram para efetivação de direitos culturais ganha destaque o direito territorial, dá-se esta ênfase porque compreende-se que esse direito, além de sua dimensão material, possui uma dimensão procedimenta|2 que é o aspecto que nos interessa nesse momento, ao se protegê-lo, protegem-se todos os direitos culturais que a Convenção $n^{\circ} 169$ visa resguardar.

Nesse mesmo sentido, Melo (2006, p. 44) afirma sobre o direito ao território ao dizer que os avanços realizados "pela Corte Interamericana no desenvolvimento do direito à propriedade em relação aos territórios indígenas estiveram orientados por uma compreensão do território como base material e espiritual dos DESq33 dos povos indígenas”.

Como se proteger o direito à manutenção de costumes e tradições indígenas sem

\footnotetext{
${ }^{2}$ Flávia Cavedon considera direitos procedimentais aqueles que propiciam a realização de outros direitos fundamentais, como ela demonstra na interpretação da Corte Europeia de Direitos Humanos sobre 0 art. $8^{\circ}$ da Convenção Europeia de Direitos Humanos quando reconheceu que "el derecho al respecto del domicílio protege el ambiente de la vida privada y familiar" (CAVEDON, 2009, p. 605), ou seja, ao se proteger o domicílio se garante o direito ao meio ambiente adequado à sadia qualidade de vida, à vida familiar e, nesse caso, à vida privada.

${ }^{3}$ Direitos Econômicos Sociais e Culturais.
} 
se garantir aos povos indígenas o território para isso? Como garantir a manutenção de suas instituições sem se garantir o meio físico necessário para isso? Como se proteger o direito à consulta prévia se não houver uma base territorial sobre a qual recaia a necessidade da consulta e a necessária deliberação da comunidade sobre assuntos que possam afetar seu território e sua vida?

\subsection{Garantia de direitos culturais}

Os direitos humanos são direitos que as pessoas têm advindos de sua condição humana e que, por isso, albergam todos os homens e mulheres. São direitos que visam garantir uma existência digna a cada um sem distinções. "En este sentido, estos derechos protegen las condiciones básicas de las que toda persona debe gozar para poder llevar una vida humana en condiciones de dignidade" (PARRA VERA et al, 2008, p. 22-21).

A cultura enquanto um modo de vida é um direito que visa garantir aos indivíduos, que constituem minorias étnicas dentro dos Estados nacionais, o direito de professar sua religião, fazer uso de sua língua e reproduzir seus costumes e tradições sem serem tolhidos pelas autoridades estatais.

Garantir esse direito é garantir dignidade aos povos indígenas, ou seja, o direito cultural faz parte do rol de direitos humanos exatamente porque a manutenção da cultura por minorias étnicas é a garantia da manutenção do seu modo de vida, é a garantia da dignidade da pessoa humana.

Não está em consonância com os princípios de garantia de direitos humanos obrigar povos e indivíduos a abandonarem sua cultura, porque é o compartilhamento dos mesmos traços identitários de um grupo social que dá sentido e significado a existência desse.

Uma vez deslocado de suas referências culturais, os indivíduos ficam deslocados do mundo, é o pertencimento a um grupo cultural que determina a identidade dos indivíduos, a cultura cria um elo entre os indivíduos.

De acordo com Sabóia (2013. p. 1), a noção de pertencer a um coletivo é a razão pelo qual o processo de construção da identidade está relacionado a questões 
culturais, uma vez que a cultura é "uma ponte entre os indivíduos, que possuem suas individualidades e angústias, a identidade coletiva aparece como um modo com o qual estes tentarão se encaixar e se perceber [...]"

A elaboração da identidade:

[...] empresta seus materiais da história, da geografia, da biologia, das estruturas de produção e reprodução, da memória coletiva e dos fantasmas pessoais, dos aparelhos do poder, das revelações religiosas e das categorias culturais. Mas os indivíduos, os grupos sociais, as sociedades transformam todos esses materiais e redefinem seu sentido em função de determinações sociais e de projetos culturais que se enraízam na sua estrutura social e no seu quadro do espaço-tempo (CASTELLS, 1999, p.23).

A identidade se forma a partir do compartilhamento da experiência social dos indivíduos uns com os outros e destes com o espaço onde vivem, o que no caso das comunidades indígenas ganha aguda importância, uma vez que a experiência social destes povos, em um dado espaço, molda a identidade daqueles que vivenciam esta experiência. Esse espaço é juridicamente conhecido como território, indispensável à reprodução cultural e física das comunidades indígenas.

\subsection{Autorreconhecimento: um direito fundamental}

O processo de assunção de uma identidade é juridicamente conhecido como autorreconhecimento, autoidentificação, autoatribuição ou autodefinição. Ki-Zerbo (2006, p. 12) afiança que sem identidade, o indivíduo se torna um objeto da história, "[...]um instrumento utilizado pelos outros, um utensílio. E a identidade é o papel assumido: é como numa peça de teatro em que cada um recebe um papel para desempenhar."

O direito ao autorreconhecimento é um direito cultural, Moreira e Pimentel (2015, p. 160) dizem que o "Direito à autoidentificação está estritamente vinculado ao direito à identidade cultural”. O reconhecimento do pluralismo cultural no interior dos Estados nacionais, obriga os Estados a respeitarem a forma como os indivíduos e os grupos se conhecem, reconhecem e se autorreconhecem.

O direito ao autorreconhecimento é corolário do direito à autodeterminação, na mesma medida em que cabe aos grupos socialmente diversificados gerir suas vidas e relações sociais, não pode caber a mais ninguém a autoridade de determinar sua 
identidade étnica:

[...] o direito à autoidentificação é uma das pedras fundamentais dos Direitos dos Povos e Comunidades Tradicionais e implica, por essência, o reconhecimento do direito de autodeterminar-se, de autogerir-se e, por via de consequência, de autorreconhecer-se, atribuindo-se identidade de forma autônoma, sem a necessidade de chancela estatal, todavia, obrigando o Estado à adoção de políticas específicas, inclusive vinculando-o na obrigação de reconhecer o autorreconhecimento (MOREIRA e PIMENTEL, 2015, p. 159).

Logo, um terceiro alheio a essas experiências não possui condições de aferir o pertencimento dos indivíduos, dos grupos a uma identidade étnica que não eles mesmos. Nada justificaria que outrem fizesse essa determinação que não os próprios sujeitos os quais a partir de suas experiências sociais ocorridas em um dado local se posicionam e se compreendem no mundo:

Na definição da identidade étnica, é essencial levar em conta as percep-
ções dos próprios sujeitos que estão sendo identificados, sob pena de se
chancelarem leituras etnocêntricas ou essencialistas dos observadores
externos provenientes de outra cultura, muitas vezes repletas de precon-
ceito. A ideia básica, que pode ser reconduzida ao próprio princípio da
dignidade da pessoa humana, é de que na definição da identidade, não
há como ignorar a visão que o próprio sujeito de direito tem de si, sob
pena de se perpetrarem sérias arbitrariedades e violências, concretas
ou simbólicas (SARMENTO, 2008, p. 30 ).

Como aduz Sarmento (2008), é exatamente sobre isso que se trata a questão principal do direito ao autorreconhecimento, sobre a garantia da dignidade humana das pessoas, ou mais especificamente, da dignidade étnica.

Primeiramente, porque dignifica ao homem pertencer a um grupo social, a sociabilidade é uma importante característica da espécie humana, é de nossa substância a sociabilidade; segundo, porque é igualmente dignificante poder se declarar membro de um grupo e ser reconhecido dessa forma, são aspectos importantes que dão sentido à existência.

Mais recentemente, em 2015, a Ministra Rosa Weber considerou que o Estado brasileiro ao incorporar a Convenção $\mathrm{n}^{\circ} 169$ da OIT, consagra o autorreconhecimento como critério determinante dos povos e populações tradicionais:

[...] a eleição do critério da autoatribuição não é arbitrário, tampouco desfundamentado ou viciado. Além de consistir em método autorizado pela antropologia contemporânea, estampa uma opção de política pública legitimada pela Carta da República, na medida em que visa à interrupção 
do processo de negação sistemática da própria identidade aos grupos marginalizados, este uma injustiça em si mesmo (WEBER, apud MOREIRA e PIMENTEL, 2015, p. 163).

Os critérios de identificação de grupos sociais diferenciados fundados em aspectos biológicos, linguísticos, ou mesmo raciais, não constituíam um método científico satisfatório, pois a identificação dos grupos dependia de um observador externo, o que muitas vezes gerava categorias desconhecidas pelos próprios segmentos sociais estudados:

\begin{abstract}
Por isso, a extrema importância das investigações de Frederik Barth, que coloca como questão central para a identificação das comunidades não as diferenças culturais entre grupos percebidas por um observador externo, mas sim os "sinais diacríticos", isto é, aquelas diferenças que os próprios atores sociais consideram significativas e que, por sua vez, são revelados pelo próprio grupo (RIOS, 2007, p .142).
\end{abstract}

Não dever ser do Estado o poder de determinar quem é ou não índio, afinal não se pode esquecer que em vários momentos da história o Estado se postou contra os povos indígenas para atender aos interesses das classes dominantes as quais o controlam.

O critério da autoidentificação foi considerado o mais adequado para se determinar o âmbito de aplicação pessoal da Convenção garantidora em face das mais diversas realidades vivenciadas pelos grupos indígenas que não poderiam ser alcançadas por enfoques sociológicos e históricos.

A realidade indígena no continente americano apresenta situações que vão de índios não contatados na vastidão da floresta amazônica a comunidades indígenas completamente integradas ao contexto nacional. Logo o sentimento de pertencimento é que determinará se um indivíduo é índio ou não.

O autorreconhecimento, portanto, implica em os indivíduos se considerarem etnicamente diversos, o reconhecimento dessa diversidade leva à autoidentificação como membro de uma comunidade etnicamente diferente da sociedade hegemônica. É essa diversidade cultural que a Convenção no 169 e a Constituição Federal buscam tutelar.

\title{
2. Identidade caboclizada no Baixo Tapajós
}

O processo histórico de dominação portuguesa na região do rio Tapajós ocasionou a desestruturação social das comunidades indígenas, fatores econômicos e políticos aumentaram a opressão sobre as comunidades indígenas, três fatores despontam como 
os principais: a) a ação dos Jesuítas impôs uma nova cosmovisão fundada na religião católica; b) a Cabanagem ocasionou a perseguição e extermínio de indígenas no Pará e c) a dinâmica da exploração da borracha. Todos esses fatores obrigaram os moradores nativos da região a ressignificarem de forma estratégica, a partir de sua própria dinâmica cultural, a nova realidade imposta pela cultura ocidental.

Dentro desse processo de ressignificação política e social, deu-se o fenômeno da caboclização dos nativos da região do rio Tapajós, Lima (1999) esclarece que a palavra caboclo denotava índio genérico, destribalizado, passou depois a significar o híbrido, o miscigenado. A caboclização está relacionada às perdas culturais indígenas.

É válido observar que esse fenômeno não se restringiu à região do Tapajós, isso ocorreu em toda a Amazônia e em outras regiões do Brasil. Houve um "abandono" estratégico da significação indígena marcada por estigmas sociais, pela assunção de uma significação mais próxima do socialmente aceitável ou tolerável pela sociedade hegemônica.

\subsection{Caboclização na Região de Tapajós}

Na região do Tapajós, a forte opressão sofrida pelas comunidades indígenas desde o início da colonização levou os indígenas a abandonarem sua identidade étnica. Viveiros de Castro diz que há uma instrumentalidade compreensível no fato de as comunidades indígenas negarem essa identidade, "elas tinham interesse em não serem perseguidas, discriminadas, excluídas, e foram assim obrigadas a abandonar sua organização social, costumes, línguas crenças e tradições?" (2015, p. 16-17).

A presença do europeu desestruturou as sociedades índias, por outro lado os índios rearticularam suas relações e reconfiguram sua cultura e identidade diante do novo contexto (BONBARDI, 2014). A caboclização dos indígenas ocorre nesse cenário.

Após o domínio dos jesuítas nas missões e o controle cultural do período pombalino, uma parte dos povos indígenas continuava vivendo às margens dos rios, porém, já não sob o padrão pré-contato. Não mais existiam povos específicos, mas tapuios, cujas línguas, sistemas de parentesco, meios de subsistência e crenças ligadas aos seus povos indígenas específicos se homogenizaram (VAZ FILHO, 2010). 
A caboclização não conduz à extinção física, ela se dá na esfera cultural que perpassa pela retirada da língua original como instrumento de comunicação, a substituição de grande parte de suas instituições, normas e valores por outros alheios aos costumes indígenas decorrentes de uma cultura genérica e empobrecida resultada da situação coIonial.

Segundo Vaz Filho (2010), foi Parker quem denominou esse processo de caboclização dos indígenas. Segundo este, esse processo foi concluído entre 1800 e 1850 , quando se instalou na região o aviamento. A identidade indígena deixou de ser assumida mais incisivamente desde a repressão à Cabanagem, no século XIX.

A coboclização dos índios se fortalece com a negativa dos próprios indígenas de sua etnicidade, por outro lado, eles jamais se reconheceram como caboclos, essa categoria foi utilizada pela antropologia e empregada sem levar em conta o autorreconhecimento das sociedades etnografadas, não podendo, portanto, ser considerada uma categoria étnica.

Na Amazônia, vários grupos sociais ligados às questões ambientais se reconhecem como seringueiros, povos da floresta, pescadores artesanais, populações tradicionais, não como caboclos (PACE, 2006). No Tapajós as populações locais não gostavam de ser chamadas nem de caboclas, nem de índias (VAZ FILHO, 2010).

Pace aduz ainda que o termo caboclo é um termo da classe media urbana que ajuda a separá-las temporal, espacial e socialmente das populações rurais. "Em certo sentido, introduz-se uma sequência evolutiva, na qual civilização 'superior' e semiselvageria 'inferior' são distanciadas. Os índios amazônicos seriam os verdadeiros selvagens" (2006, p. 87). A condição indígena é tida como inferior à do caboclo, uma vez que estes não são mais "selvagens" recaindo esse estigma sobre a figura do índio.

O termo caboclo, no contexto amazônico, é empregado como uma categoria relacional que identifica pessoas em posição social inferior em relação a posição com que o locutor se identifica incluindo qualidades rurais, descendência indígena, analfabeta e rústica. Como categoria relacional caboclo é sempre o outro, assim não existem grupos que se identifiquem fixamente como caboclos sendo aplicado a qualquer grupo social ou pessoa indígena, rural ou rústica (LIMA, 1999). 
O caboclo é uma categoria de classificação social empregada por estranhos, com base no reconhecimento de que a população rural amazônica compartilha um conjunto de atributos comuns. Mas esta não é uma categoria social homogênea nem absolutamente distintiva. É importante frisar a natureza conceitual do termo pois existe o perigo de tomar-se o termo caboclo como uma identidade e desse modo criar fronteiras absolutas para um grupo social que não é encontrado na vida real (LIMA, 1999, p. 8).

São atributos econômicos, políticos e culturais que determinam a categoria social caboclo, refere-se, portanto, a pequenos produtores de base familiar amazônicos que sobrevivem do extrativismo (LIMA, 1999).

A categorização dos índios como caboclos se deve a um senso comum que concebe o indígena apenas na sua "forma pura", a do índio tribal. Nessa forma de pensar falta o reconhecimento de que a identidade é um nexo de relações e transações com a qual os indivíduos estão ativamente comprometidos, "fazendo com que a continuidade destas culturas fosse alcançada, não na permanência estática, mas sim nos modos peculiares pelos quais elas se transformam" (CYPRIANO, 2007, p. 140).

As sociedades indígenas não são sociedades estáticas, estão sujeitas à dinâmica cultural como qualquer sociedade que mantenha ou não contatos culturais. Não é um conjunto de itens que possa distinguir esse ou aquele grupo, é exatamente o contrário disso, o intercâmbio é intenso e as trocas permanentes facilitando as relações sociais (BELTRÃO, 2015).

\subsection{Reconhecimento de direitos pela descaboclização}

A grande questão sobre processo de caboclização está relacionada ao fato de os diversos povos indígenas do Baixo Tapajós terem "perdido" suas identidades étnicas específicas, tornando-se todas elas em uma única e homogênea massa cultural de onde não se distinguia um Tupinambá de uma Apiaká, um Tapajó de um Arapium:

O nome que tem os Tapuios- chamados também Caboclos- não envolve nenhuma ideia de procedência especial, posto que eles se liguem provavelmente pela maior parte do tronco tupi, cujos os vários dialetos se pareciam com o que os jesuítas methodicamente transcreveram (RECLUS apud BELTRÃO, 2015, p. 15).

Deve-se enfatizar que isso foi resultado do processo cultural imposto pelo sistema colonial de forma violenta e cruel. O termo caboclo reflete a incompreensão da soci- 
edade envolvente desse processo histórico que dizimou e desorganizou as sociedades indígenas na Amazônia.

Não obstante a esse cenário histórico de ressignificação étnica, hoje, com o reconhecimento dos direitos culturais, essa lógica se inverte, neste sentido, propôs-se que a mesma razão que fez os índios se caboclizarem, agora faz com que eles busquem indianizar-se: O desejo de continuar existindo da forma como eles querem continuar existindo.

Com o empoderamento político, a identidade indígena, antes escondida e negada, passa a ser assumida. Diversos relatos dão conta da vergonha de ser índio, mesmo lideranças indígenas assumem que tinham vergonha de ser índio, mas hoje exaltam o orgulho de o ser.

Um coordenador da Coordenação Geral das Organizações Indígenas da Amazônia Brasileira (COIAB), em 1999, em uma missa indígena em Suruacá, admitiu que na juventude tinha vergonha de suas origens (VAZ FILHO, 2010). Mesmo pessoas com traços visivelmente indígenas negavam sua condição étnica (ALMEIDA, 2001).

A partir daqui, passaremos a enfocar mais precisamente ao que levou à mudança de atitude quanto à identidade indígena na região do rio Tapajós, onde várias comunidades rurais passaram a se autoreconhecer como indígenas.

\section{Identidades ressurgidas}

O autorreconhecimento, enquanto um direito fundamental cultural, promoveu, dentro da sociedade brasileira pós-Constituição de 1988 garantidora de direitos pluriétnicos e multiculturais, o ressurgimento de identidades étnicas que há muito se haviam empalidecido diante da dominação da cultura dominante. Esse fenômeno social a antropologia categorizou como etnogênese.

A etnogênese, no sentido de ressurgimento de comunidades indígenas pelo autorreconhecimento, é um fenômeno político decorrente desse direito. O forte processo integracionista que promoveu a deculturação de muitos povos indígenas reforça este fenômeno, pois muitas comunidades indígenas submetidas ao processo assimilacionista, buscam hoje, resgatar sua identidade étnica. É nesse exato contexto em que se encon- 
tram muitas comunidades rurais do Baixo Tapajós.

Bartolomé (2006, p. 52) discorre que a etnogênese, em sentido atual, não possui um aspecto rígido, imutável, pois "[...] pode ser modificada, recriada e inclusive construída ou reconstruída de acordo com as necessidades dos atores".

Essa tomada de consciência étnica ocorre, especialmente, porque esta autoafirmação gera direitos fundamentais para povos que durante toda a história de dominação da cultura europeia, não os teve. Esta garantia de direitos influencia na forma como se dá a constituição da identidade étnica fortalecendo esses laços identitários.

Além dos direitos fundamentais gerados por esse autorreconhecimento, advindos da Constituição Federal e dos tratados firmados pelo Brasil, para essa tomada de consciência "Concorre também o desejo de pertencer a um povo, a um lugar e a uma luta" (PINTO, 2012, p. 77).

No processo estabelecido pela etnogênese, deve-se observar as relações sociais havidas entre os membros de uma mesma sociedade, dessas relações sociais e da afetividade advinda delas nasce o sentimento de pertencimento. Neste sentido, é por meio dessas relações que os indivíduos identificam-se uns aos outros e se autoidentificam como membros de uma comunidade étnica.

\subsection{O movimento indígena no Baixo Tapajós: revitalização étnica}

O movimento indígena no Tapajós está diretamente inserido no contexto social exposto alhures, por essa razão o fenômeno de autoafirmação étnica intensifica-se na década de 90, não obstante tenha iniciado em 1974 quando da criação da Floresta Nacional do Tapajós (FLONA Tapajós) em 1974. Essa unidade de conservação não admitia a presença da população nativa em seu interior.

Isso gerou imediato conflito com as populações locais, totalmente "[...] desconsideradas do processo de criação, as comunidades locais renegaram as tentativas de desapropriação e têm rejeitado as propostas de delimitação de uma área que elas consideram insuficientes para suprir suas necessidades" (IORIS, 2000, p.3). A criação da Floresta Nacional do Tapajós foi marcada pelo autoritarismo e arbitrariedade.

Entretanto as comunidades não aceitaram deixar suas terras, tem início aí o movi- 
mento de resistência dos moradores da FLONA, mesmo assim comunidades ainda foram extintas:

[...] o IBDF começou um processo de desapropriação das populações locais de suas áreas, cujos procedimentos foram contestados, reivindicando o direito de permanecer em suas terras. Apesar desta demanda, O IBDF chegou a desapropriar diversas famílias ao longo da rodovia Santarém-Cuiabá, no rio Cupari, e na margem direita do rio Tapajós, extinguindo, desta forma, comunidades como São João, Jacamim e Terra Rica (IORIS, 2000, p. 5).

Diante da resistência dos comunitários, o Instituto Brasileiro de Desenvolvimento Florestal (IBDF), antecessor do Instituto Brasileiro do Meio Ambiente e dos Recursos Naturais Renováveis (IBAMA), promoveu uma reunião em Santarém no dia 9 de maio de 1983 propondo a exclusão de uma área da FLONA para atender às comunidades.

loris (2000) relata que algumas das comunidades da FLONA, percebendo essa posição de desvantagem na relação com o IBAMA, buscaram solucionar seu problema recorrendo à Fundação Nacional do Índio. Esse sentimento de pertencimento havido do conflito entre as comunidades e o Estado vai desembocar em um forte movimento de revitalização da identidade indígena em toda a região a partir da década de 90:

Na Floresta Nacional Tapajós (Flona), em 1998, uma comunidade se autodeclarou Munduruku. Esse foi o início do movimento indígena que reivindica direitos indígenas, especialmente a garantia de seu território e o reconhecimento da sua identidade. Atualmente, 48 comunidades se declaram indígenas no baixo Tapajós (PEIXOTO e PEIXOTO, 2012, p. 20).

Diversas comunidades passaram a reivindicar identidades étnicas: Arara Vermelha-Tupaiu, Munduruku, Arapium, Jaraqui, Tapajó, Borari, Munduruku-Apiaká, Tupinambá, Munduruku-Cara Preta, Maitapu, Yawaretê, Kumaruara (COSTA et al, 2013).

\subsection{Expansão do movimento étnico no Baixo Tapajós}

Mais contemporaneamente, o fato propulsor da emergência étnica no Baixo Tapajós e no Arapiuns aconteceu na comunidade da Takuara com a morte do pajé Laurelino em 1998, morador da FLONA Tapajós (COSTA et al, 2013):

Lá, a lembrança das práticas de cura do pajé Laurelino, e suas orientações ao grupo para que não se esquecessem de sua origem indígena, no momento de sua morte, foram decisivos para o processo de reafirmação étnica das famílias e serviu de catalisador do movimento indígena nos rios Tapajós e Arapiuns (SILVA, 2007, p. 33). 
Os habitantes de Taquara se autorreconheceram como Munduruku sendo seguidos pelas comunitários de Bragança e de Marituba. Alguns anos depois a FUNAI reconheceu essas comunidades como indígenas (PEIXOTO et al, 2012). O movimento indígena expandiu-se por todo o Tapajós e alcançou os rios Arapiuns e Maró como forma de reação dos habitantes nativos à organização fundiária imposta pelo Estado.

Esse movimento indígena vai ao encontro do que Boal (2009) propõe ao reconhecer que em cada sociedade tem opressores e oprimidos e que os primeiros impõem aos segundos sua visão de mundo para que sejam obedecidos. Os oprimidos para se libertarem devem descobrir sua própria visão da sociedade, suas necessidades e opor-se à opressiva verdade dominante. Assumir-se índio em um espaço em que eram tidos por extintos desde a segunda metade do século XVIII, é impor uma visão de mundo que visa romper com a opressão.

No Baixo Tapajós e no Arapiuns, o movimento iniciado com familiares e seguidores do falecido pajé Laurelino espalhou-se em um crescente processo de aglutinação, extrapolando os limites da FLONA Tapajós, alcançando outras comunidades localizadas em áreas onde o modelo fundiário implantado também não favorecia ao modo de vida tradicional, ocasionando tensão entre os comunitários e os órgãos governamentais.

Além da FLONA Tapajós, ocorreu também, na Reserva Extrativista TapajósArapiúns (RESEX Tapajós-Arapiuns), no PAE Lago Grande, na Gleba Nova Olinda e no Planalto Santareno, a insatisfação das comunidades com o modelo fundiário implantado.

\begin{abstract}
O movimento de reafirmação étnica que hoje caracteriza o Baixo Tapajós nasceu, pois, da articulação política dos habitantes nativos para a defesa de um território que, nos anos 1970, começava a ser apropriado e organizado sob uma lógica totalmente distinta daquela até então vigente, expressas nas ações do INCRA e do Iterpa voltadas para os não-índios que começavam a chegar na área. Significativamente, a população nativa teve imensa dificuldade para se adaptar aos projetos de assentamento, desenhados de acordo com a lógica capitalista de apropriação privada da terra e dos recursos naturais (TEMPESTA, 2011, p. 1).
\end{abstract}

A vontade de ser um sujeito de direito fez com que as comunidades restaurassem suas identidades étnicas como instrumento de luta e de resistência contra a hegemonia da racionalidade econômica capitalista. 


\section{Considerações Finais}

A luta dos povos indígenas do Brasil confluiu para a criação de diversos direitos que não apenas lhes eram negados, como também eram ignorados pela sociedade hegemônica, a sensibilidade jurídica monista do Estado não alcançava as particularidades culturais característica de cada povo. As políticas assimilacionistas que buscavam integrar o índio ao modelo de sociedade nacional, levaram os povos indígenas a questionar o caráter fatídico de sua extinção étnica e a se insurgir contra isso.

O movimento indígena se levantou em uma luta conceitual sobre quem seria índio, para o movimento, a condição indígena não poderia ser vista como uma condição transitória rumo ao branqueamento. Não poderia ser considerado índio só quem fosse índio "puro", a mestiçagem não poderia suplantar a identidade indígena.

A essa luta somou-se também, a dos povos indígenas da Amazônia que tiveram seus territórios e modos de vida ameaçados pelos megaprojetos econômicos do período militar. Loureiro e Pinto (2005) informam que até a década de 1960, quando iniciam-se os grandes projetos, não havia conflito por terra na Amazônia.

Como fruto dessas lutas, a legislação passou a respaldar os direitos indígenas concebendo-os como produto de uma construção social que venceu arcaicos conceitos. O sucesso do movimento indígena se vê refletido em um arcabouço de proteção jurídica nacional e internacional que garante seu território e sua cultura como exemplificam o art. 231-CF que prevê o direito territorial aos povos indígenas e a Convenção nº 169 da OIT.

A emergência desses povos não se deu gratuitamente. Antes, fora resultado de uma série de acontecimentos que confluíram para o resgate identitário como mais um mecanismo de sobrevivência com o fim de continuar existindo da forma como se designam a viver em um livre exercício de autodeterminação.

Essa pesquisa teve o firme propósito de demostrar que aspectos genéticos e diacríticos culturais não são elementos que devam ser levados em consideração para determinar quem é ou não índio. Essa identificação deve ser feita pelas próprias pessoas a partir do seu sentimento de pertencimento a um grupo e a um lugar. É essa identificação que dá propósito a existência das pessoas autoidentificadas e permite a elas encontrarem seu lugar no mundo. 


\section{Referências}

ALMEIDA, Rita Heloísa. Relatório de viagem ao rio Tapajós. Ministério da Justiça: Fundação Nacional do Índio, 2001.

AMORIM, Siloé Sares de. A construção da autoimagem. Os Tumbalalá, os Kalankó, os Karuazo, os Catókinn e os Koiupanka. Dissertação de Mestrado, Campinas, 2003.

BARTOLOMÉ, Miguel Alberto. As etnogêneses: velhos atores e novos papéis no cenário cultural e político. Mana. Estudos de Antropologia Social, 12(1): 39-68, 2006.

BELTRÃO, Jane Felipe. Parecer sobre a Ação Civil Pública 2091-80.2010. Solicitação do Ministério Público Federal- Santarém/Pa, 2015.

BOAL, Augusto. Estética do oprimido. Rio de Janeiro: Garamond, 2009.

BOMBARDI, Fernanda Aires. Pelos interstícios do olhar do colonizador: descimento de índios no Estado do Maranhãoe Grão-Pará(1680-1750). Dissertação apresentada ao Programa de Pós-graduação em História Socialda Universidade de São Paulo. São Paulo, 2014

BRASIL. Advocacia Geral da União. Contestação nos autos do processo n 20112091 80.2010.4.01.3902, 2011

Decreto $\mathrm{n}^{\circ}$ 5.051, de 19 de abril de 2004. Disponível em: <http://www.planalto.gov.br/ccivil_03/_a to2004-2006/2004/decreto/d5051.htm> Acesso em 03 de agosto de 2018.

. Ministério Público Federal. Câmara de Coordenação e Revisão, 6. Territórios de povos e comunidades tradicionais e as unidades de conservação de proteção integral: alternativas para o asseguramento de direitos socioambientais / 6 . Câmara de Coordenação e Revisão; coordenação Maria Luiza Grabner; redação Eliane Simões, Débora Stucchi. Brasília : MPF, 2014.

CASTELLS, Manuel. O Poder da Identidade. Vol. II. São Paulo: Editora Paz e Terra, 1999.

CAVEDON, Fernanda de Salles. Justicia Ambiental y Creación Jurisprudencial Del Derechos Humanos. Universidade de Alicante - Espanha, 2009.

COSTA, Solange Maria Gayoso da; VIEIRA, Judith Costa; LIMA, Marcos Vinicius Costa e MILEO, Bruno Paracampo. Territorialização e identidade indígena no Baixo Tapajós no Estado do Pará. VI Jornada Internacional de Políticas Públicas. Agosto de 2013.

CYPRIANO, Doris Cristina Castilhos de Araujo. Almas, corpos e especiarias: A expansão colonial nos rios Tapajós e Madeira. Instituto Anchietano de Pesquisas, São Leopoldo: Unisinos, 2007.

HALL, Stuart. A identidade cultural na pós-modernidade. $11^{\text {a }}$ Ed. Rio de Janeiro: DP\&A, 2006.

KI-ZERBO, Joseph. Para quando África? Rio de Janeiro: Pallas, 2006.

IORIS, Edviges Marta. Conflitos em unidades de conservação com populações locais: $O$ caso da Floresta Nacional do Tapajós. XXII Reunião Brasileira de Antropologia. Brasília, julho de 2000. 
LIMA, Débora Magalhães. A construção histórica do termo caboclo sobre estruturas e representações sociais no meio rural amazônico. Novos Cadernos NAEA vol. 2, $n^{\circ} 2$ dezembro 1999.

LOUREIRO, Violeta Refkalesfsky; PINTO, Jax Nildo Aragão. Dossiê Amazônia Brasileira II: A questão fundiária na Amazônia. Instituto de Estudos Avançados da Universidade de São Paulo, 2005.

MACEDO, Marcus Vinícios Aguiar. Populações e Terras Indígenas na Amazônia. In Vida e Morte na Amazônia Indígena. As invasões madeireiras e os povos Ashaninka. Rio Branco: Editora Ufac. 2009. p. 85-144.

MELO, Mario. Últimos Avanços na Justiciabilidade dos Direitos Indígenas no Sistema Interamericano de Direitos Humanos. SUR - Revista Internacional de Direitos Humanos, Número 4, Ano 3, 2006.

MOREIRA, Eliane; PIMENTEL, Melissa. O Direito à Autoidentificação de Povos e Comunidades Tradicionais no Brasil. Revista Fragmentos de Cultura, Goiânia, v. 25, n. 2, p. 159-170, abr./jun. 2015.

ORGANIZAÇÃO INTERNACIONAL DO TRABALHO, Convenção n' 169 sobre povos indígenas e tribais e Resolução referente à ação da OIT / Organização Internacional do Trabalho. - Brasilia: OIT, 2011.

PARRA VERA, Oscar; HERMIDA, María Aránzazu Villanueva; MARTIN, Agustín Enrique. Protección internacional de los derechos económicos, sociales y culturales: Sistema Universal y Sistema Interamericano. Instituto Interamericano de Derechos Humanos. San José, C.R.: IIDH, 2008.

PINTO, Paulo Gabriel Hilu da Rocha. Grupos étnicos e etnicidade. In Antropologia e Direito: temas antropológicos para estudos jurídicos/ coordenação geral [de] Antonio Carlos de Souza Lima. - / Rio de Janeiro / Brasília: Contra Capa / LACED / Associação Brasileira de Antropologia,2012, p. 68-77.

PACE, Richard. Abuso científico do termo 'caboclo'? Dúvidas de representação e autoridade. Bol. Mus. Para. Emílio Goeldi, Ciências Humanas, Belém, v. 1, n. 3, p. 79-92, set-dez. 2006.

PEIXOTO, Kércia Priscilla Figueiredo; PEIXOTO, Rodrigo. A luta territorial dos indígenas da Terra Maró. Somanlu, ano 12, n. 2, jul./dez. 2012.

RIOS, Aurélio Virgílio. Quilombos na Perspectiva da Igualdade Etnico-Racial: raízes, conceitos, perspectivas In. Duprat, Deborah. Pareceres Jurídicos - Direito dos Povos e das Comunidades Tradicionais. Manaus: UEA, 2007.

SABÓIA, Evandro Finardi. Identidade e cultura: reflexões sobre autoidentificação racial no Brasil. Este texto é parte das reflexões desenvolvidas no âmbito da realização da pesquisa A PERSISTÊNCIA DAS IDEIAS DE "RAÇA" E "DEMOCRACIA RACIAL": UMA ANÁLISE DAS REPRESENTAÇÕES E PERCEPÇÔES SOBRE RACISMO E PRÁTICAS RACISTAS NA CIDADE DE SÂOO PAULO, realizada com bolsa do Programa FESPSP $\mathrm{PIBIC/CNPq}$ e vigência entre 2012-2013.

SALGADO, Juan Manuel. El convenio 169 da OIT: comentado y anotado. $1^{\text {a }}$ ed. 
Neuquén: EUDUCO- Universidad Nacional del Comahue, 2006.

SARMENTO, Daniel. Territórios Quilombolas e Constituição: A ADI 3.239 e a Constitucionalidade do Decreto 4.887/03. Parecer jurídico. MPF: Rio de Janeiro, 2008.

SILVA, Raphael Frederico Acioli Moreira da. Relatório de viagem às aldeias indígenas Novo Lugar, Cachoeira do Maró e São José II, situadas no rio Maró, Gleba Nova Olinda. Ministério Público Federal: Procuradoria da República no Município de Santarém/Pa. 2007.

TEMPESTA, Giovana Acacia. Procedimento de identificação e delimitação da TI Maró (Pa). Ministério da Justiça: Fundação Nacional do Índio. Informação n 42/CGDI/2011, 2011.

VAZ FILHO. F. A. A emergência étnica dos povos indígenas do baixo Rio Tapajós, Amazônia. 2010. 478f. Tese (Doutorado em Ciências Sociais - área de concentração Antropologia), Universidade Federal da Bahia, Salvador, 2010. 